\title{
Use of the Side-Reaction Coefficient for the Speciation of Copper(II) in Natural Water Samples
}

\author{
Hideyuki Itabashi, Hiroshi Kawamoto and Hideo Akaiwa \\ Department of Applied Chemistry, Faculty of Engineering, Gunma University, \\ Kiryu, Gunma 376, Japan
}

Keywords Speciation, copper(II), liquid-liquid extraction, side-reaction coefficient, river water sample

A wide variety of methods have been proposed and used for the determination of trace metal ions in natural water samples. However, trace metal analysis without speciation has only poor environmental significance, since the toxicity of a metal to aquatic organisms depends heavily on its chemical form. ${ }^{1}$ From this aspect, the authors developed methods for estimating the copper(II) complexing capacity and lability of the copper(II) complex ${ }^{2,3}$, and then applied these methods to riverwater samples. ${ }^{4-6}$ In the present work, a preconcentration technique based on a liquid-liquid extraction of copper(II) with 4,4,4-trifluoro-1-(2-thienyl)-1,3-butanedione (TTA) was developed into a method for the speciation of copper(II). In this speciation method, not only the total amount of copper(II), but the degree of complexation of copper(II) in natural water samples are estimated through the side-reaction coefficient of copper(II) with a naturally occurring ligand.

\section{Theory}

It is àssumed that the main reaction is the extraction of copper(II) with TTA, while the side reaction is complexation of copper(II) with a ligand (L) in a water sample. The extraction reaction of copper(II) with TTA can be expressed by

$$
\mathrm{Cu}^{2+}+2 \mathrm{Htta}_{\text {org }} \rightleftharpoons \mathrm{Cu}(\mathrm{tta})_{2, \text { org }}+2 \mathrm{H}^{+}
$$

and the extraction constant $\left(K_{\mathrm{ex}}\right)$ is defined as

$$
K_{\mathrm{ex}}=\frac{\left[\mathrm{Cu}(\mathrm{tta})_{2}\right]_{\text {org }}\left[\mathrm{H}^{+}\right]^{2}}{\left[\mathrm{Cu}^{2+}\right][\mathrm{Htta}]_{\text {org }}^{2}},
$$

where the subscript org denotes the organic phase and $\mathrm{Htta}=$ TTA.

On the other hand, the complexation of copper(II) with a ligand $(\mathrm{L})$ is assumed to proceed as

$$
\mathrm{Cu}^{2+}+\mathrm{L} \rightleftharpoons \mathrm{CuL}
$$

for which the stability constant $(\beta)$ is defined by

$$
\beta=\frac{[\mathrm{CuL}]}{\left[\mathrm{Cu}^{2+}\right][\mathrm{L}]} \text {. }
$$

The concentration of copper(II) in the aqueous phase can be expressed as

$$
\begin{aligned}
{\left[\mathrm{Cu}^{\mathrm{II}}\right]_{\mathrm{aq}} } & =\left[\mathrm{Cu}^{2+}\right]+[\mathrm{CuL}] \\
& =\left[\mathrm{Cu}^{2+}\right] \alpha_{\mathrm{L}},
\end{aligned}
$$

where the subscript (aq) denotes the aqueous phase, and $\alpha_{\mathrm{L}}=1+\beta[\mathrm{L}]$. The absolute amount of copper(II) in the extraction system is expressed by

$$
\mathrm{Cu}^{\mathrm{II}}=V_{\mathrm{aq}}\left[\mathrm{Cu}^{\mathrm{II}}\right]_{\mathrm{aq}}+V_{\mathrm{org}}\left[\mathrm{Cu}^{\mathrm{II}}\right]_{\mathrm{org}} \text {, }
$$

where $V_{\text {aq }}$ and $V_{\text {org }}$ are the volumes of the aqueous and organic phases. Upon introducing Eqs. (2) and (5) into Eq. (6) one obtains

$$
\frac{1}{\left[\mathrm{Cu}^{\mathrm{II}}\right]_{\text {org }}}=\frac{V_{\text {org }}}{\mathrm{Cu}^{\mathrm{II}}}+\frac{\alpha_{\mathrm{L}} V_{\mathrm{aq}}\left[\mathrm{H}^{+}\right]^{2}}{K_{\mathrm{ex}} \mathrm{Cu}^{\mathrm{II}}[\mathrm{Htta}]_{\text {org }}^{2}} .
$$

According to Eq. (7), a plot of $1 /\left[\mathrm{Cu}^{\mathrm{II}}\right]_{\text {org }}$ against $\left[\mathrm{H}^{+}\right]^{2} /$ $[\mathrm{Htta}]_{\text {org }}^{2}$ should give a straight line having a slope of $\alpha_{\mathrm{L}} V_{\text {aq }} /\left(K_{\text {ex }} \mathrm{Cu}^{\text {II }}\right)$ and an intercept $V_{\text {org }} / \mathrm{Cu}^{\mathrm{II}}$. If $K_{\text {ex }}$ is known, the $\alpha_{\mathrm{L}}$ value can be calculated from the slope and intercept. Here, $\alpha_{\mathrm{L}}$ is a value of environmental significance indicating the degree of complexation of copper(II). ${ }^{7}$

\section{Experimental}

\section{Apparatus}

A Shimazu (Model AA-630-12) atomic absorption spectrophotometer equipped with a graphite-furnace atomizer (GF-AAS) was used. A Horiba (Model F-80) $\mathrm{pH}$ meter and an Iwaki (KM-type) shaker were used for pH measurements and shaking of the separatory funnels, respectively. 


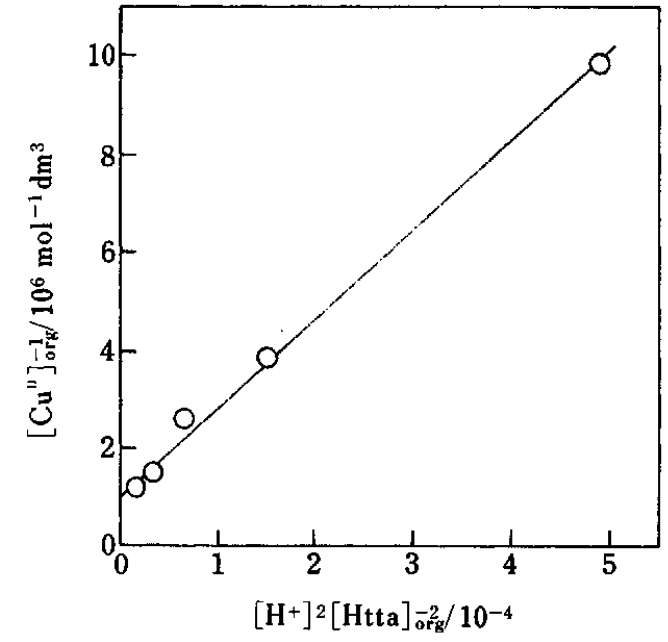

Fig. $11 /\left[\mathrm{Cu}^{11}\right]_{\text {org }}$ vs. $\left[\mathrm{H}^{+}\right]^{2} /[\mathrm{Htta}]_{\text {org. }}^{2} . \mathrm{Cu}^{\mathrm{II}}, 1.5 \times 10^{-8} \mathrm{~mol}$; NTA, $1.0 \times 10^{-6} \mathrm{~mol} \mathrm{dm}^{-3} ; \mathrm{pH}, 4.67 \pm 0.11$.

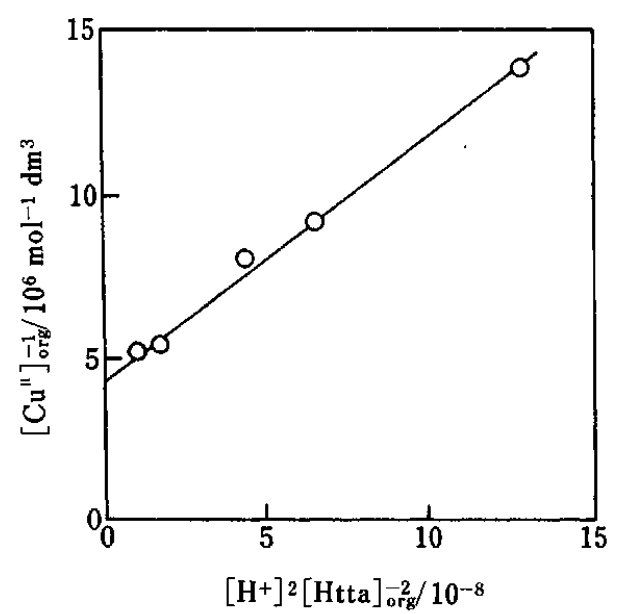

Fig. $21 /\left[\mathrm{Cu}^{\text {"I }}\right]_{\text {org }} v s$. $\left[\mathrm{H}^{+}\right]^{2} /[\mathrm{Htta}]_{\text {org }}^{2}$. The water sample was taken from Kiryu River; $\mathrm{pH}, 6.80 \pm 0.02$.

\section{Reagents}

Stock solutions of copper(II) and nitrilotriacetic acid (NTA) $\left(1 \times 10^{-3} \mathrm{~mol} \mathrm{dm}^{-3}\right)$ were prepared by dissolving $0.250 \mathrm{~g}$ of copper(II) sulfate pentahydrate and $0.235 \mathrm{~g}$ of nitrilotriacetic acid disodium salt in $1000 \mathrm{~cm}^{3}$ of water, respectively. A stock solution of TTA $\left(2 \times 10^{-2} \mathrm{~mol}\right.$ $\mathrm{dm}^{-3}$ ) was prepared by dissolving $0.444 \mathrm{~g}$ of TTA in $100 \mathrm{~cm}^{3}$ of carbon tetrachloride. All of the reagents used were of analytical grade, and were used without further purification. Deionized distilled water was used throughout the experiments.

\section{Procedure}

To $50 \mathrm{~cm}^{3}$ of a water sample solution in a separatory funnel was added $1 \mathrm{~cm}^{3}$ of a $5 \mathrm{~mol} \mathrm{dm}^{-3}$ sodium perchlorate aqueous solution. Then, $5 \mathrm{~cm}^{3}$ of a TTA solution was added, and the mixture was shaken for $30 \mathrm{~min}$. After the phases were allowed to separate, the organic phase was applied to GF-AAS and the pH of the aqueous phase was measured. All of the experiments were carried out at room temperature (ca. $293 \mathrm{~K}$ ).

\section{Results and Discussion}

In order to obtain $K_{\text {ex }}$, the experiment was carried out in the presence of a known amount of $\mathrm{Cu}^{\mathrm{II}}\left(=1.5 \times 10^{-8}\right.$ mol) and NTA $\left(=1.0 \times 10^{-6} \mathrm{~mol} \mathrm{dm}^{-3}\right)$ as a representative of naturally occurring ligands. The side-reaction coefficient of copper(II) with NTA $\left(\alpha_{\mathrm{L}}\right)$ was calculated by using the reported stability constant for the NTA complex. $^{8}$ The results are given in Fig. 1; the plots fall on a straight line, indicating that Eq. (7) is valid. $K_{\text {ex }}$ was calculated to be 0.10 and $\mathrm{Cu}^{\mathrm{II}}$ was $1.5 \times 10^{-8} \mathrm{~mol}$, which agreed with the amount of $\mathrm{Cu}^{\mathrm{II}}$ added.

Finally, the present method was applied to a natural water sample. The water sample was taken from Kiryu River and filtered through a $0.45 \mu \mathrm{m}$ membrane filter. An analysis was carried out according to the procedure described above. The plots obtained on the basis of Eq. (7) are given in Fig. 2, where a straight line can be seen. The estimated total concentration of copper(II) and the side-reaction coefficient $\left(\alpha_{\mathrm{L}}\right)$ were $2.3 \times 10^{-8}$ mol dm $\mathrm{dm}^{-3}$ and $1.6 \times 10^{5}$, respectively. From this results, it was found that most of the copper(II) exists as complexes with naturally occurring ligands; the free concentration of copper(II) was estimated to be $1.4 \times$ $10^{-13} \mathrm{~mol} \mathrm{dm}^{-3}$.

The authors wish to express their thanks to Mr. W. Ishida for his experimental assistance. We also gratefully acknowledge the financial support of this study by a grant-in-Aid for Scientific Research (No. 03453040) from the Ministry of Education, Science and Culture.

\section{References}

1. T. M. Florence and G. E. Batley, Talanta, 24, 151 (1977).

2. H. Akaiwa, H. Kawamoto and H. Ogura, Chem. Lett., 1986, 605 .

3. H. Kawamoto, R. Yokoyama, K. Tsunoda and H. Akaiwa, Anal. Sci., 8, 571 (1992).

4. M. Uchiyama, H. Kawamoto, H. Itabashi and $H$. Akaiwa, Nippon Kagaku Kaishi, 1989, 309.

5. H. Kawamoto, W. Ishida, K. Tsunoda and H. Akaiwa, Bull. Chem. Soc. Jpn., 65, 3485 (1992).

6. H. Kawamoto, R. Yokoyama, K. Tsunoda and $\mathbf{H}$. Akaiwa, Bull. Chem. Soc. Jpn., 66, 2104 (1993).

7. G. G. Leppard, "Trace Element Speciation in Surface Waters", Plenum Press, New York, 1983.

8. T. Sakaguchi and K. Ueno, "Kinzoku Kireito (Metal Chelates, in Japanese) [III]", Appendix p. 26, Nankoh Dow, Tokyo, 1967.

(Received October 15, 1993) (Accepted February 7, 1994) 